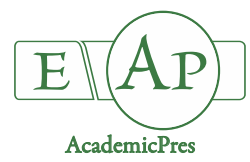

\title{
Antioxidant Properties and Anti-inflammatory Effects of the Hydroethanolic Extracts of Two Varieties of Bayberry fruit (Myrica rubra Sieb et Zucc.) Prepared by Stirring and Ultrasonic Methods
}

\author{
Kuan-Hung LIN ${ }^{1}$, Chun-Ping $\mathrm{LU}^{2}$, Jia-Wei CHAO${ }^{1}$, Yi-Ping YU ${ }^{3 *}$ \\ ${ }^{1}$ Chinese Culture University, Graduate Institute of Biotechnology, Taipei 11114, Taiwan; rlin@faculty.pccu.edu.tw; nsr.tigra@gmail.com \\ ${ }^{2}$ Fu Jen Catholic University, Department of Food Science, New Taipei City 24205, Taiwan; 089984@mail.fju.edu.tw \\ ${ }^{3}$ Chinese Culture University, Department of Nutrition and Health Sciences, Taipei 11114, \\ Taiwan; yyp@faculty.pccu.edu.tw (*correspondingauthor)
}

\begin{abstract}
Chinese bayberry (Myrica rubra Sieb. et Zucc.) is an economically important medicinal plant with multiple uses. Two varieties 'Dongkui Oriental Pearl' (Dongkui for short) and acuminata 'Nakai' (Nakai for short) were used to compare and evaluate the antioxidant activities of hydroethanolic extracts of the fruit using ultrasonic and stirring extraction methods. Dongkui bayberry fruit extract (BFE) prepared using the ultrasonic method exhibited a significantly higher value for the total phenolic content (TPC) and had lower $50 \%$ inhibitory concentration $\left(\mathrm{IC}_{50}\right.$ ) values of scavenging activities against 1,1diphenyl-2- picrylhydrazyl (DPPH), 2,2'-azino-bis (3-ethylbenzothiazoline-6-sulphonic acid (ABTS), and hydrogen peroxide $\left(\mathrm{H}_{2} \mathrm{O}_{2}\right)$, as well as reducing power compared to the other treatment. The TPC of the BFE was significantly correlated with its DPPH, ABTS, and $\mathrm{H}_{2} \mathrm{O}_{2}$ radical-scavenging and reducing power activities. Dongkui BFE at a concentration of $0.25 \mathrm{mg} / \mathrm{mL}$ exhibited significantly greater protection of RAW 264.7 mouse macrophages against $\mathrm{H}_{2} \mathrm{O}_{2}$-induced damage and lipopolysaccharide (LPS)-stimulated nitric oxide production by macrophages, and it displayed remarkable inhibitory effects compared to the other extracts using the ultrasonic extraction method. Furthermore, compared to the Nakai BFE, macrophages exposed to the Dongkui BFE by the ultrasonic extraction method significantly inhibited LPS-induced production of tumor necrosis factor- $\alpha$ at a concentration of the extract of $0.25 \mathrm{mg} / \mathrm{mL}$. The antioxidant properties and antiinflammatory and protective effects of BFE prepared by stirring and ultrasonic methods are discussed for the first time in this study.
\end{abstract}

Keywords: antioxidant activity; bayberry fruit extract; free radical scavenging; Myrica rubra; ultrasonics

\section{Introduction}

Chinese bayberry (Myrica rubra Sieb. et Zucc.), of the Myricaceae family, is native to eastern Asia. Depending on the cultivar, ripe Chinese bayberry fruits can be purple, red, pink, or white, and they all have an attractive flavor and taste sour but delicious. All parts of the bayberry plant are used in Chinese traditional medicine, and the fruits are used to treat vomiting, diarrhea, and abdominal pain (Sun et al., 2012; Silva et al., 2015). Several studies reported that Chinese bayberry fruit is rich in phytochemicals and bioactive compounds that are beneficial to human health due to their antioxidant (Silva et al., 2015), antihyperlipidemic (Jurgonski et al., 2008), anti-diarrheal (Yao et al., 2011), anticancer (Yang et al., 2011), anti- inflammatory (Farrell et al., 2015; Silva et al., 2015), antidiabetic (Zhang et al., 2016), anti-obesity (Meireles et al., 2016), antibacterial (Ju et al., 2018), and anti-melanogenesis properties (Juang et al., 2018). In addition to the commercial fruit, the consumption of wild and underutilized fruits is also gaining importance owing to their antioxidant contents and consequent health benefits. The aim of studying such underutilized crops is to promote their conservation as potential sources of antioxidants and boost agronomic advancement to economically uplift local farming communities. A number of wild but potentially commercial fruits are available in Taiwan, among which, the red-fruited Chinese bayberry varieties locally known as Dongkui and Nakai are among high-value edible fruits. They are also highly perishable and susceptible to mechanical injury, physiological deterioration, and fungal 
decay (Wang et al., 2010). It would be advantageous to assess the antioxidant properties of these fruits for possible use in creating functional foods or for consideration as potential sources of natural antioxidants.

There is great interest in the use of potent dietary antioxidants in preventive strategies with applications ranging from preventing oxidative reactions in foods and pharmaceuticals to the role of reactive oxygen species (ROS) in chronic degenerative diseases (Farombi et al., 2004). Although several varieties of bayberries are known to be potent sources of antioxidant compounds (Silva et al., 2015), no literature on the antioxidant properties of Chinese bayberry fruit against free radical-induced oxidative stress in in vitro cell experiments is presently available. Relationships between antioxidant activities and the prevention of cell oxidative damage by bayberry fruit extracts (BFEs) are not well researched. Extraction is the first step in the commercial isolation of antioxidant components. It is worth exploring essential applications of BFEs in foods which can enhance the nutritional quality and therapeutic value, and also provide income for bayberry producers and the regional economy. In addition, there is a need to find a single or a group of effective extraction methods for bayberry fruit that can produce natural antioxidant agents, which would likely have important applications in the food and medical industries.

Comparisons of extraction processes of bioactive compounds from plants between traditional (maceration, agitation, Soxhlet, and hydrodistillation) and novel (enzyme, microwave, ultrasound-assisted, and using supercritical fluids) were reported (Wang and Weller, 2006; Ghafoor et al., 2011; Radojković et al., 2012; Azmir et al., 2013; Li et al., 2013; Medina-Torres et al., 2017). Vega Arroy et al. (2017) showed that ultrasound processes significantly increased the antioxidant capacity and total anthocyanins and phenolic compounds of $x^{\prime}$ kijit (Renealmia alpinia Rottb. Maas) peel extracts while reducing extraction times and increasing the energy efficiency compared to Soxhlet extraction. Thus, in this study, we compared and evaluated the antioxidant properties of BFEs using stirring and ultrasonic methods with $85 \%$ ethanol, and studied the effects of total phenols, flavonoids, anthocyanins, and antioxidant activities of the two varieties that can protect and inhibit oxidative damage to mouse RAW 264.7 macrophages induced by $\mathrm{H}_{2} \mathrm{O}_{2}$. In addition, the protective effects of $M$. rubra extracts were also evaluated against lipopolysaccharide (LPS)-stimulated nitric oxide (NO) and the proinflammatory cytokine tumor necrosis factor (TNF)- $\alpha$.

\section{Materials and Methods}

Source of plants and preparation of plant extracts

Two varieties of red bayberry fruits, Nakai and Dongkui, are popular among local residents, and were collected from a commercial orchard in Keelung City, northern Taiwan in July 2015. The cultivars acuminate Nakai and Dongkui (Orient Pearl) of Myrica rubra were identified according to the List of Plants of Formosa (http ://tai2 .ntu. edu. tw/ PlantInfo/species-name.php?code $=302 \% 20001 \%$
2002\%200), and voucher specimen number TAIID65696 was deposited at the National Taiwan University herbarium (Yang and Lu, 1996). Dongkui has been planted islandwide and is the most popular variety on the market due to its large fruit size compared to the Nakai variety that originates from Taiwan and is mostly planted in southern Taiwan. All bayberries were randomly harvested according to the shape and uniform color at their commercially mature stage. After being harvested, freshly picked bayberry fruit samples were carefully washed with tap water, lyophilized using a freeze dryer (FD-5060, Panchum Scientific, Taipei, Taiwan), and stored at $-20{ }^{\circ} \mathrm{C}$. After milling, $10 \mathrm{~g}$ of lyophilized fruit was mixed in separate bottles with $500 \mathrm{~mL}$ of ethanol/water $(85: 15, \mathrm{v} / \mathrm{v})$, followed by treatment with ultrasonic bath shaking (DELTA ultrasonic cleaner DC150H, New Taipei City, Taiwan, at $40 \mathrm{kHz}$ and $150 \mathrm{~W}$ ) for $6 \mathrm{~h}$ at room temperature to ensure that all of the colored ingredients were extracted (Kumoro and Hartati, 2015). For the stirring method, the abovedescribed $85 \%$ hydroethanolic extracts were treated by stirring with an electromagnetic stirrer (Corning PC-400D, New York, NY, USA) for $6 \mathrm{~h}$ at room temperature. The extracts were then transferred to a rotary evaporator (Buchi R-205, Flawil, Switzerland) under reduced pressure to remove the ethanol until a thick, viscous solution was obtained. Finally, the viscous solutions were frozen at low temperature until solid and then were subjected to a freezedrying process to remove any water residue. The extraction yield (\%) was calculated as the dry extract weight (g) divided by the dry sample weight (g, dry mass) $x 100 \%$. The hydroethanolic extract was then stored at $-20^{\circ} \mathrm{C}$ until being used for the antioxidant activity assays.

Analysis of the total phenol content (TPC), total flavonoid content (TFC), and total anthocyanin content (TAC)

The TPC was assayed from the Nakai and Dongkui BFEs with the Folin-Ciocalteau reagent, using gallic acid as a standard (Lee et al., 2018). Three hundred microliters $(\mu \mathrm{L})$ of Folin-Ciocalteau reagent (diluted 10-fold in distilled-deionized water, $\mathrm{ddH}_{2} \mathrm{O}$ ) and $240 \mu \mathrm{L}$ of a $1 \mathrm{M}$ sodium bicarbonate solution were added to $30 \mu \mathrm{L}$ of each BFE. After incubation for $15 \mathrm{~min}$ at $20^{\circ} \mathrm{C}$, the absorbance at $765 \mathrm{~nm}$ was read. The TPC was expressed as $\mathrm{mg}$ gallic acid equivalents (GAE)/g dry extract. The linear range of the calibration curve was $27 \sim 150 \mu \mathrm{g} / \mathrm{mL}$ ( $r=0.9988$ ).

The TFC was determined according to the method described by Kashiwada et al. (2005). Six hundred microliters of BFE was mixed with an equal volume of $10 \%$ $\mathrm{AlCl}_{3}$. After incubation for $15 \mathrm{~min}$, the absorbance at 510 $\mathrm{nm}$ was read. The TFC, using quercetin as a standard, was expressed as $\mathrm{mg}$ quercetin equivalents $(\mathrm{QE}) / \mathrm{g}$ dry extract. The linear range of the calibration curve was $6.25 \sim 50$ $\mu \mathrm{g} / \mathrm{mL}(r=0.9982)$.

The TAC was determined according to a previously described procedure by Padmavati et al. (1997). Briefly, 100 $\mu \mathrm{L}$ of the BFE was added to $10 \mathrm{~mL}$ of $1 \% \mathrm{HCl} / \mathrm{MeOH}$ and thoroughly mixed. The mixture was placed in the dark at 4 ${ }^{\circ} \mathrm{C}$ for $2 \mathrm{~h}$, after which it was centrifuged at $4{ }^{\circ} \mathrm{C}$ and 1000 $\times g$ for $15 \mathrm{~min}$. The absorbance of the supernatant was measured at 530 and $657 \mathrm{~nm}$. TAC $(\mu \mathrm{mol} / \mathrm{g})=\left[3 \mathrm{x}\left(\mathrm{A}_{530}-\right.\right.$ $\left.0.33 \times \mathrm{A}_{657}\right)$ ] / 31.6 . 
636

Measurement of the scavenging activities against the 1,1diphenyl-2-picrylhydrazyl (DPPH) and 2,2-azino-bis-(3ethyl benzothiazoline-6-sulfonicacid) (ABTS) radicals

Scavenging activities against the DPPH radical by fruit hydroethanolic extracts were determined by previously published methods (Lee et al., 2018). Briefly, an aliquot of $70 \mu \mathrm{L}$ of serially diluted extracts was added to $140 \mu \mathrm{L}$ of 150 $\mu \mathrm{M}$ DPPH freshly prepared in methanol, mixed well, and left to stand for $30 \mathrm{~min}$ at room temperature in the dark to allow the reaction to precede. DPPH radicals are scavenged by antioxidants through the donation of electrons. The color changes from purple to yellow after reduction, which can be quantified by the decrease in absorbance at a wavelength of $517 \mathrm{~nm}$. The scavenging effect $(\%)=[1-$ (absorbance of a sample) / (absorbance of a blank DPPH solution)] x 100. The blank was treated in the same manner, except that methanol was used instead of a sample, and ascorbic acid was used as the control. The concentration required for a $50 \%$ decrease in the absorbance of DPPH radicals $\left(\mathrm{IC}_{50}\right)$ was calculated as the percent inhibition of $\mathrm{DPPH}$, and each sample was measured with at least three different concentrations in the $\mathrm{DPPH}$ test. The $\mathrm{IC}_{50}$ was obtained by plotting the percentage of residual DPPH at a steady state as a function of the antioxidant concentration.

Scavenging activities against the ABTS radical cation by fruit hydroethanolic extracts were determined by the method of Re et al. (1999). Total antioxidant capacities of hydrophilic antioxidants were determined using the horseradish peroxidase (HRP)-catalyzed oxidation of ABTS. The reaction mixture contained $0.1 \mathrm{~mL}$ of $1 \mathrm{mM}$ ABTS, $100 \mu \mathrm{L}$ of $44 \mathrm{U} / \mathrm{mL}$ peroxidase, $0.1 \mathrm{~mL}$ of $0.5 \mathrm{mM}$ $\mathrm{H}_{2} \mathrm{O}_{2}$, and $600 \mu \mathrm{L}$ of $\mathrm{ddH}_{2} \mathrm{O}$. After $1 \mathrm{~h}, 0.01 \mathrm{~mL}$ of BFE was added to the mixture, and after $10 \mathrm{~min}$, the absorbance was measured at $734 \mathrm{~nm}$. Trolox (TR) was used as a standard. The $\mathrm{IC}_{50}$ value was obtained by interpolation from a linear regression analysis.

Measurement of the $\mathrm{H}_{2} \mathrm{O}_{2}$-scavenging capacity of the BFE

Hydrogen peroxide was added to each test sample and assayed in a 96-well microplate. Each well contained $100 \mu \mathrm{L}$ of $4 \mathrm{mM} p$-nitrophenylboronic acid (NPBA) and $100 \mu \mathrm{L}$ of each sample (Lu et al., 2011). Blank solutions were prepared by mixing $100 \mu \mathrm{L}$ of a sample solution with an equal volume of $150 \mathrm{mM}$ carbonate/bicarbonate buffer at $\mathrm{pH} 9.0$. The plates were vortexed, and the reactions were then allowed to proceed for $20 \mathrm{~min}$ at room temperature. The absorbance at $405 \mathrm{~nm}$ was recorded. The absorbance of the blank was subtracted from the absorbance of the respective samples.

\section{Measurement of the reducing power}

The reducing power of the extracts was determined according to the method of Lee et al. (2018). Briefly, an aliquot of $20 \mu \mathrm{L}$ of the hydroethanolic extract was mixed with an equal volume of $0.2 \mathrm{M}$ sodium phosphate buffer (pH 6.6) and $1 \%$ potassium ferricyanide. The mixture was incubated at $50{ }^{\circ} \mathrm{C}$ for $20 \mathrm{~min}$. After cooling down on ice, $80 \mu \mathrm{L}$ of $\mathrm{ddH}_{2} \mathrm{O}, 20 \mu \mathrm{L}$ of $10 \%$ trichloroacetic acid, and 80 $\mu \mathrm{L}$ of $0.1 \%$ ferric chloride were added to the mixture. After $15 \mathrm{~min}$, the absorbance at $700 \mathrm{~nm}$ was measured against a blank. The blank was prepared using $95 \%$ ethanol with no extract. An increase in the absorbance of the reaction mixture indicated a higher reducing power. Ascorbic acid was used as a standard. $\mathrm{EC}_{50}$ was effective concentration at the absorbance is 0.5 .

Protective effect of the BFE against $\mathrm{H}_{2} \mathrm{O}_{2}$-induced oxidative stress

RAW 264.7 cells $\left(10^{5}\right.$ cells/well $)$ were incubated overnight in plates containing $50 \mu \mathrm{L}$ of the BFE $(0.025 \sim 2.5$ $\mathrm{mg} / \mathrm{mL}$ ), followed by the addition of $50 \mu \mathrm{L}$ of $1.2 \mathrm{mM}$ $\mathrm{H}_{2} \mathrm{O}_{2}$ to each well; this was allowed to react for $24 \mathrm{~h}$ at 37 ${ }^{\circ} \mathrm{C}$. After that, $50 \mu \mathrm{L}$ of MTT $(0.5 \mathrm{mg} / \mathrm{mL})$ was added and allowed to react for $2 \mathrm{~h}$ at $37^{\circ} \mathrm{C}$. After draining, cells were washed with phosphate-buffered saline (PBS), dissolved in $150 \mu \mathrm{L}$ DMSO, and monitored for absorbance at $570 \mathrm{~nm}$ using a Microplate reader (Molecular Devices SpetraMax 190, San Jose, CA, USA) for cell viability: Cell viability (\%) $=\left[\left(\mathrm{A}_{570}\right.\right.$ of the extract-treated group $) /\left(\mathrm{A}_{570}\right.$ of the blank group)] x 100 (\%). The control contained $\mathrm{H}_{2} \mathrm{O}_{2}$ and no added sample extract. The blank was only DMEM without $\mathrm{H}_{2} \mathrm{O}_{2}$ or sample extract.

\section{Measurement of the inbibitory effect on NO production}

$\mathrm{NO}$, a potentially toxic molecule is released by innate immune cells during pathogenesis, and its production is involved in the response to lipopolysaccharide (LPS)stimulated RAW 264.7 macrophages. Therefore, NO liberated from RAW 264.7 macrophages were measured by the Griess assay (Green et al., 1982) in this study. Briefly, RAW 264.7 macrophages $\left(10^{5}\right.$ cells/well) were incubated for $24 \mathrm{~h}$. Cells were then stimulated with LPS $(1 \mu \mathrm{g} / \mathrm{mL})$, and treated with each individual BFE sample at concentrations ranging from 0.025 to $2.5 \mathrm{mg} / \mathrm{mL}$ for $24 \mathrm{~h}$ at $37^{\circ} \mathrm{C}$. The medium was then mixed with an equal volume of Griess reagent (Sigma, St. Louis, MO, USA). The amount of $\mathrm{NO}$ was quantified by measuring the absorbance at $540 \mathrm{~nm}$ using a microplate reader, and was determined using a sodium nitrite standard curve.

Analysis of proinflammatory cytokine secretions as determined using enzyme-linked immunosorbent assays (ELISAs)

Anti-inflammatory effects of the BFE were analyzed in LPS-induced RAW 264.7 cells. Cells were seeded in 96-well culture plates at a density of $10^{5}$ cells/well, followed by incubation for $24 \mathrm{~h}$. Cells were then exposed to $1 \mu \mathrm{g} / \mathrm{mL}$ of LPS, treated with each individual BFE sample (0.025 2.5 $\mathrm{mg} / \mathrm{mL}$ ), and incubated for $24 \mathrm{~h}$ at $37^{\circ} \mathrm{C}$. Levels of TNF- $\alpha$ in the culture media were determined by a Duo Set mouse TNF- $\alpha$ Sandwich ELISA kit, according to the manufacturer's protocols (R\&D Systems, Minneapolis, MN, USA). TNF- $\alpha$ standard at $0 \sim 2 \mathrm{mg} / \mathrm{mL}$ were used to create a standard curve to calculate the TNF- $\alpha$ contents.

\section{Statistical analysis}

All analyses were conducted in triplicate, and results are expressed as the mean and standard deviation (SD). An analysis of variance (ANOVA) with Duncan test at 0.05 was performed using the SAS program vers. 9 (SAS Institute, Cary, NC, USA).

Pearson's correlation coefficients of total phenols, flavonoids, anthocyanin, DPPH, ABTS, $\mathrm{H}_{2} \mathrm{O}_{2}$, and the reducing power after treatment with $\mathrm{BFE}$ were also determined. 


\section{Results}

Analysis of the TPCs, TFCs, and TACs of the BFEs

The TPCs, TFCs, and TACs of extracts from the two varieties and from the two different extraction methods were analyzed by spectrophotometry (Table 1). The Dongkui variety of BFE contained a significantly higher TPC than that of Nakai. Moreover, the BFE prepared by the ultrasonic method had a significantly higher TPC compared to the stirring method. The highest $(18.50 \pm 0.29$ $\mathrm{mg} \mathrm{GAE} / \mathrm{g}$ extract) and lowest (11.10 $\pm 0.68 \mathrm{mg} \mathrm{GAE} / \mathrm{g}$ extract) TPCs were respectively found in the Dongkui sample prepared by ultrasonics and in the Nakai sample prepared by stirring. TFCs of all test samples ranged from $2.23 \pm 0.15$ (Dongkui prepared by the ultrasonic method) to $2.69 \pm 0.44 \mathrm{mg} \mathrm{QE} / \mathrm{g}$ extract (Dongkui prepared by the stirring method), and no significant differences were detected among the various samples. No significant differences in TACs (which ranged $2.44 \pm 0.42 \sim 2.77 \pm$ $0.38 \mu \mathrm{mol} / \mathrm{g}$ extract) appeared among all test samples regardless of the variety or extraction method. In addition, the extraction yields (\%) of the two bayberry varieties using different extraction methods were $40.3 \%$ (Nakai by ultrasonics), 38.5\% (Nakai by stirring), 41.8\% (Dongkui by ultrasonics), and 39.8\% (Dongkui by stirring).

Ability of $M$. rubra fruit extracts to scavenge the DPPH, ABTS, and $\mathrm{H}_{2} \mathrm{O}_{2}$ radicals and their in vitro reducing power

Myrica rubra extracts were tested for their antioxidant activities, and results from Table 2 show that $\mathrm{IC}_{50}$ values of DPPH with Dongkui BFEs prepared by both methods $(0.65 \pm 0.01 \sim 0.71 \pm 0.02 \mathrm{mg} / \mathrm{mL})$ were significantly lower than those of Nakai BFEs $(1.32 \pm 0.11 \sim 1.53 \pm 0.01$ $\mathrm{mg} / \mathrm{mL})$. In addition, Dongkui BFEs prepared by both methods also had significantly lower $\mathrm{IC}_{50}$ values of ABTS radical scavenging than the other test samples, and the
Dongkui BFE prepared by sonication had the highest activity compared to the others. The Dongkui BFE prepared by sonication also had the highest $\mathrm{H}_{2} \mathrm{O}_{2}$ scavenging activity at $1.83 \pm 0.13 \mathrm{mg} / \mathrm{mL}$ of extract, followed by the Dongkui BFE prepared by stirring (3.97 \pm $0.87 \mathrm{mg} / \mathrm{mL})$, and Nakai BFEs prepared by both methods $(11.05 \pm 0.16$ and $11.79 \pm 0.68 \mathrm{mg} / \mathrm{mL})$. The BFEs exhibited significant differences in the ferric-reducing antioxidant power as they exhibited a wide range of $\mathrm{EC}_{50}$ values of $2.78 \pm 0.09$ (Nakai BFE prepared by the stirring method) to $0.39 \pm 0.01 \mathrm{mg} / \mathrm{mL}$ (Dongkui BFE prepared by the sonication method). Therefore, the Dongkui BFE prepared by sonication displayed the best antioxidant activity in all in vitro antioxidant experiments.

\section{Correlation coefficients between in vitro antioxidant activities of the BFEs}

Correlation coefficients of TFC, TFC, TAC, and the DPPH-, ABTS-, and $\mathrm{H}_{2} \mathrm{O}_{2}$-scavenging activity assays are shown in Table 3. Significant positive correlations $(r=$ $0.93 \sim 0.99$ ) were found among DPPH scavenging, ABTS scavenging, reducing power, and $\mathrm{H}_{2} \mathrm{O}_{2}$ scavenging. According to the TPC assay, the $\mathrm{IC}_{50}$ of antioxidant activity was significantly and negatively associated with the contents of DPPH, ABTS, and $\mathrm{H}_{2} \mathrm{O}_{2}$, and the reducing power $(r=-$ $0.80 \sim-0.83$ ). However, no correlations were observed for the remaining antioxidant activity assays.

Protective effects of BFEs against $\mathrm{H}_{2} \mathrm{O}_{2}$-induced oxidative stress in $R A W 264.7$ mouse macrophages

Protective effects of the BFEs against $\mathrm{H}_{2} \mathrm{O}_{2}$-induced oxidative stress in RAW 264.7 mouse macrophages are illustrated in Fig. 1. All BFEs produced significantly higher cell survivability compared to the control at all extract concentrations except for Dongkui BFE prepared by the ultrasonic method at $0.025 \mathrm{mg} / \mathrm{mL}$.

Table 1. Total phenols (TPC), total flavonoids (TFC), and total anthocyanins (TAC) contents of extracts from two bayberry varieties using ultrasonic and stirring extractions methods

\begin{tabular}{|c|c|c|c|}
\hline & $\begin{array}{c}\text { TPC } \\
\text { (mg of GAE } / \mathrm{g} \text { ) }\end{array}$ & $\begin{array}{c}\text { TFC } \\
(\mathrm{mg} \mathrm{QE} / \mathrm{g})\end{array}$ & $\begin{array}{c}\text { TAC } \\
(\mu \mathrm{mol} / \mathrm{g} \text { extract })\end{array}$ \\
\hline \multicolumn{4}{|c|}{ Nakai } \\
\hline Ultrasonics & $13.41 \pm 1.08^{b}$ & $2.41 \pm 0.26^{a}$ & $2.44 \pm 0.42^{\mathrm{a}}$ \\
\hline Stirring & $11.10 \pm 0.68^{c}$ & $2.66 \pm 0.30^{a}$ & $2.61 \pm 0.12^{a}$ \\
\hline \multicolumn{4}{|c|}{ Dongkui } \\
\hline Ultrasonics & $18.50 \pm 0.29^{\mathrm{a}}$ & $2.23 \pm 0.15^{\mathrm{a}}$ & $2.77 \pm 0.38^{2}$ \\
\hline Stirring & $14.18 \pm 0.28^{b}$ & $2.69 \pm 0.44^{\mathrm{a}}$ & $2.68 \pm 0.18^{\mathrm{a}}$ \\
\hline
\end{tabular}

Each value is expressed as the mean \pm SD $(n=3)$.

Means with different letters significantly differ $(p<0.05)$ among extraction methods and varieties.

GAE, gallic acid equivalent; QE, quercetin equivalent.

Table 2. Antioxidant activities of extracts of two bayberry varieties using ultrasonic and stirring methods

\begin{tabular}{|c|c|c|c|c|}
\hline & DPPH & ABTS & $\mathrm{H}_{2} \mathrm{O}_{2}$ & Reducing power \\
\hline & & $\mathrm{IC}_{50}(\mathrm{mg} / \mathrm{mL})$ & & $\mathrm{EC}_{50}(\mathrm{mg} / \mathrm{mL})$ \\
\hline \multicolumn{5}{|c|}{ Nakai } \\
\hline Ultrasonics & $1.32 \pm 0.14^{\mathrm{b}}$ & $4.81 \pm 0.63^{a}$ & $11.05 \pm 0.16^{a}$ & $1.70 \pm 0.06^{\mathrm{b}}$ \\
\hline Stirring & $1.53 \pm 0.01^{\mathrm{a}}$ & $5.05 \pm 0.04^{\mathrm{a}}$ & $11.79 \pm 0.68^{a}$ & $2.78 \pm 0.09^{\mathrm{a}}$ \\
\hline \multicolumn{5}{|c|}{ Dongkui } \\
\hline Ultrasonics & $0.65 \pm 0.01^{c}$ & $1.54 \pm 0.01^{c}$ & $1.83 \pm 0.13^{c}$ & $0.39 \pm 0.01^{\mathrm{d}}$ \\
\hline Stirring & $0.71 \pm 0.02^{c}$ & $2.18 \pm 0.01^{b}$ & $3.97 \pm 0.87^{b}$ & $0.53 \pm 0.03^{c}$ \\
\hline
\end{tabular}

Each value is expressed as the mean \pm SD $(n=3)$.

The half-inhibitory concentration (IC50) was calculated as the antioxidant concentration required to provide $50 \%$ of the antioxidant activity.

$\mathrm{EC}_{50}$ is the effective concentration used for the reducing power when the absorbance is 0.5 .

Means with different letters significantly differ $(p<0.05)$ among extraction methods and varieties. 
638

Table 3. Correlation coefficients among total phenols, total flavonoids, total anthocyanins, DPPH, ABTS, $\mathrm{H}_{2} \mathrm{O}_{2}$, and the reducing power of bayberry fruit extracts

\begin{tabular}{|c|c|c|c|c|c|c|}
\hline & IC 50 of ABTS & $\begin{array}{l}\text { EC50 of the } \\
\text { reducing power }\end{array}$ & $\mathrm{IC}_{50}$ of $\mathrm{H}_{2} \mathrm{O}_{2}$ & ТPC & TFC & TAC \\
\hline $\mathrm{IC}_{50}$ of DPPH & $0.99^{* *}$ & $0.97^{* *}$ & $0.97^{* *}$ & $-0.80^{*}$ & $0.28^{\mathrm{NS}}$ & $-0.16^{\mathrm{NS}}$ \\
\hline IC 50 of ABTS & - & $0.93^{* *}$ & $0.98^{* *}$ & $-0.80^{*}$ & $0.27^{\mathrm{NS}}$ & $-0.20^{\mathrm{NS}}$ \\
\hline EC50 of Reduction power & - & - & $0.93^{* *}$ & $-0.82^{*}$ & $0.28^{\mathrm{NS}}$ & $-0.19^{\mathrm{NS}}$ \\
\hline $\mathrm{IC}_{50}$ of $\mathrm{H}_{2} \mathrm{O}_{2}$ & - & - & - & $-0.83^{*}$ & $0.31^{\mathrm{NS}}$ & $-0.27^{\mathrm{NS}}$ \\
\hline TPC & - & - & - & - & $-0.35^{\mathrm{NS}}$ & $0.34^{\mathrm{NS}}$ \\
\hline TFC & - & - & - & - & - & $0.47^{\mathrm{NS}}$ \\
\hline
\end{tabular}

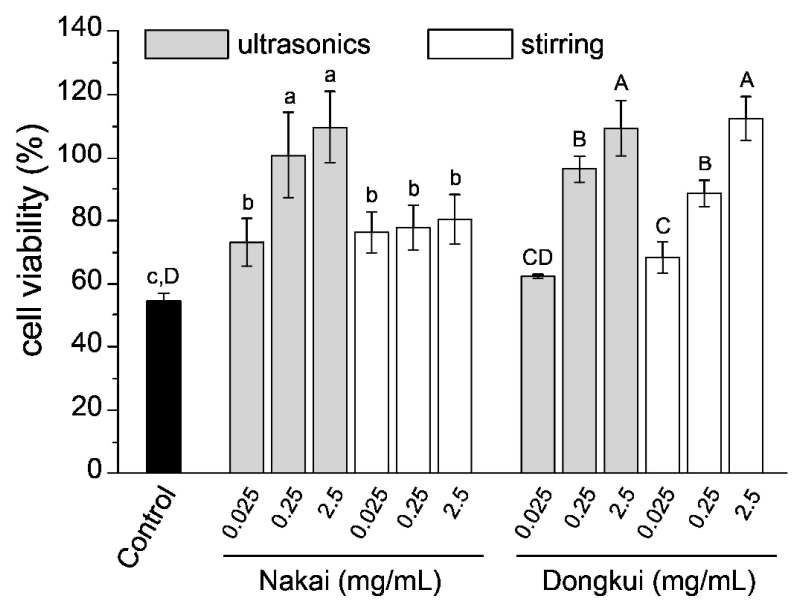

Fig. 1. Protective effects of extracts of two bayberry varieties using different extraction methods against hydrogen peroxideinduced oxidative stress in RAW 264.7 cells. Each value is expressed as the mean $\pm \mathrm{SD}(n=3)$. Among six treatments for each extraction method of the same variety compared to the control, means with the same lowercase and capital letter in the 'Nakai' and 'Dongkui' BFEs, respectively, do not significantly differ by Duncan test at $p \leq 0.05$. Cell viability $(\%)=\left[\left(\mathrm{A}_{570}\right.\right.$ of extract-treated group $) /\left(\mathrm{A}_{570}\right.$ of blank group $\left.)\right] \times 100$. The blank was DMEM only without $\mathrm{H}_{2} \mathrm{O}_{2}$ or sample extracts. The control was $\mathrm{H}_{2} \mathrm{O}_{2}$ only without sample extracts

Among them, the Nakai BFE prepared by the ultrasonic method at both 0.25 and $2.5 \mathrm{mg} / \mathrm{mL}$ showed the best protective effects against $\mathrm{H}_{2} \mathrm{O}_{2}$-induced oxidative stress.

In addition, significantly higher cell viability values with the Dongkui BFE prepared by both methods were observed at the concentrations of 0.25 and $2.50 \mathrm{mg} / \mathrm{mL}$ compared to the control.

\section{Inbibitory effects on $N O$ contents}

In order to examine the anti-inflammatory potential, the inhibitory effects of various BFEs on the production of $\mathrm{NO}$ were evaluated in LPS-stimulated RAW 264.7 macrophages. Nitrite, a stable oxidized form of $\mathrm{NO}$ produced by inducible NO synthase (iNOS), was measured

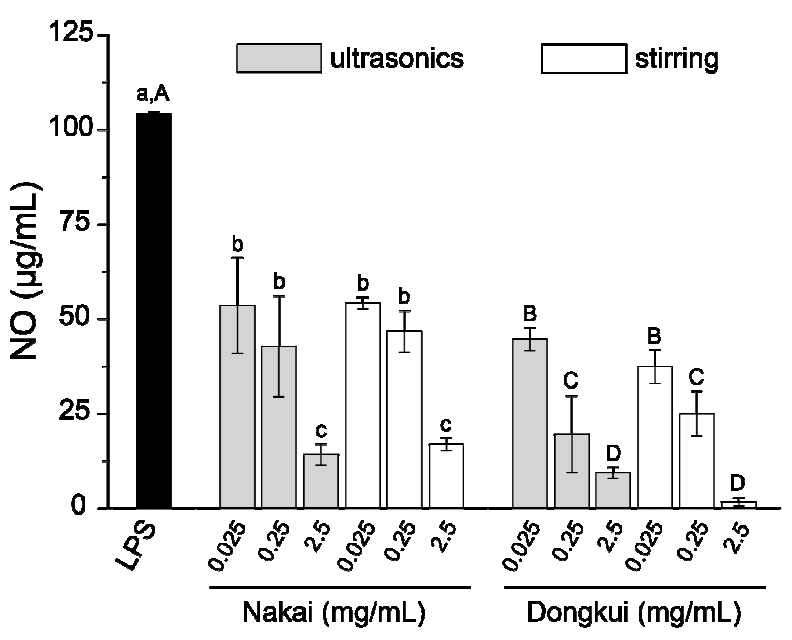

Fig. 2. Nitric oxide (NO) contents of extracts of two bayberry varieties using different extraction methods against lipopolysaccharide (LPS)-induced inflammation of RAW 264.7 cells. Each value is expressed as the mean $\pm \operatorname{SD}(n=3)$. The control was only LPS without sample extract. Among six treatments for each extraction method of the same variety compared to the control, means with the same lowercase and capital letter in the 'Nakai' and 'Dongkui' BFEs, respectively, do not significantly differ by Duncan test at $p \leq 0.05$.

as a proxy for $\mathrm{NO}$ production in the medium. As shown in Fig. 2, all BFEs produced significantly higher inhibitory effects compared to the control.

At a concentration of $2.5 \mathrm{mg} / \mathrm{mL}$, the Nakai NBE prepared by both the ultrasonic and stirring methods produced relatively lower amounts of $\mathrm{NO}$ at $14.18 \pm 2.84$ and $16.88 \pm 1.67 \mu \mathrm{g} / \mathrm{mL}$, respectively. At a concentration of $2.5 \mathrm{mg} / \mathrm{mL}$, the Dongkui BFEs prepared by both the stirring and ultrasonic methods displayed remarkable inhibitory effects at $1.68 \pm 1.07$ and $9.38 \pm 1.47 \mu \mathrm{g} / \mathrm{mL}$, respectively. In addition, the inhibitory effect gradually increased as the Dongkui BFE concentration increased, suggesting that the BFE inhibited $\mathrm{NO}$ production in a dosedependent manner. 


\section{Effects of BFEs on TNF- $\alpha$ production}

Fig. 3 shows the effect of treatments with various BFEs on TNF- $\alpha$ production measured by an ELISA in supernatants of RAW 264.7 cells treated with extracts for $24 \mathrm{~h}$ before LPS stimulation. There were no significant differences between the control and Nakai BFEs prepared by either extraction method at any concentration, except for the Nakai BFE prepared by the ultrasonic method at 2.5 $\mathrm{mg} / \mathrm{mL}$, which showed an inhibitory effect on the TNF- $\alpha$ content. As the BFE concentration increased, macrophages treated with the Dongkui BFEs prepared by both methods induced significantly higher inhibitory effects on TNF- $\alpha$, indicative of a dose-dependent response. Compared to the stirring method, the Dongkui BFE prepared by the ultrasonic method at concentrations of 0.25 and $2.5 \mathrm{mg} / \mathrm{mL}$ produced significantly higher inhibitory effects on TNF- $\alpha$ secretion against LPS-induced inflammation in RAW 264.7 cells. Furthermore, compared to the Nakai BFE, macrophages treated with the Dongkui BFE induced relatively lower levels of TNF- $\alpha$ at extract concentrations of 0.25 and $2.5 \mathrm{mg} / \mathrm{mL}$.

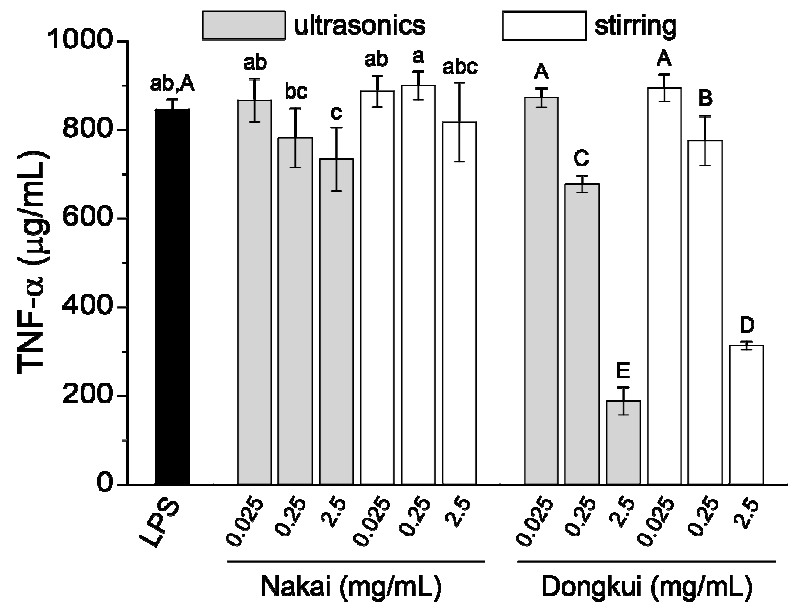

Fig. 3. Tumor necrosis factor (TNF)- $\alpha$ contents of extracts of two bayberry varieties using different extraction methods against lipopolysaccharide (LPS)-induced inflammation of RAW 264.7 cells. Each value is expressed as the mean \pm SD (n $=3$ ). The control was only LPS without sample extract. Among six treatments for each extraction method of the same variety compared to the control, means with the same lowercase and capital letter in the 'Nakai' and 'Dongkui' BFEs, respectively, do not significantly differ by Duncan test at $p \leq$ 0.05 .

\section{Discussion}

Different bayberry fruit varieties subjected to different extraction methods showed antioxidant activities, proving their capacity to scavenge DPPH, ABTS, and $\mathrm{H}_{2} \mathrm{O}_{2}$ radicals and their reducing power. Apparently, the Dongkui BFE had higher antioxidant contents compared to the Nakai BFE, suggesting that different BFE samples can play important roles in antioxidant activity. Antioxidant abilities of the Dongkui BFE prepared by both extraction methods were significantly higher than those of the Nakai BFE. In particular, the Dongkui BFE prepared by sonication had higher scavenging efficacies for DPPH, ABTS, and $\mathrm{H}_{2} \mathrm{O}_{2}$ radicals compared to the other test samples, reflecting the relevance of evaluating the major mechanisms of antioxidant actions in cell protection. Moreover, the Dongkui BFE prepared by sonication is an electron donor and can react with free radicals, convert them to more-stable products, and terminate radical chain reactions. The known mechanisms of antioxidants are to provide hydrogen or to act as chelating agents to react with free radicals and then form stable molecules to stop free radical chain reactions. The antioxidant activity of the BFE involves scavenging free radical ions, thereby inhibiting their oxidation ability.

In our study, the reducing power activities and $\mathrm{IC}_{50}$ values of DPPH, ABTS, and $\mathrm{H}_{2} \mathrm{O}_{2}$ radicals and the $\mathrm{EC}_{50}$ of the reducing power by the BFEs were highly and significantly associated with the TPC $(r=-0.80 \sim-0.83)$, indicating positive relationships among DPPH॰-, ABTS•,and $\mathrm{H}_{2} \mathrm{O}_{2}$ radical-scavenging activities, reducing power values, and the TPC. These results suggest that phenolic compounds are effective hydrogen donors. Therefore, the excellent antioxidant activities of the BFEs indicate high TPCs, and the test samples have great potential for development into phenolic-rich functional food products. Our results are consistent with previous studies (Zhou et al., 2009; Huang et al., 2014), and suggest that there is a strong correlation between antioxidant activities and TPCs of Chinese bayberry. In addition, Chen et al. (2016) reported that various amounts of phenolics $(0.47 \sim 2.31 \mathrm{~g} \mathrm{GAE} / \mathrm{kg})$ and flavonoids (0.34 2.08 g rutin equivalents $/ \mathrm{kg})$ were found in all tested bayberry varieties. The antioxidant activity of bayberry was highly correlated with the phenolic contents, including flavonoids. Hong et al. (2008) demonstrated that the ferric-reducing ability exhibited good linear correlations with the antioxidant activity and TFCs or TPCs in Eriobotrya species. Using other antioxidant evaluation methods based on different mechanisms to evaluate the antioxidant activity may produce different results even from the same sample. Furthermore, different extraction solvents resulted in differences in the compositions of the extracts, and consequently their antioxidant activities (Pinelo et al., 2004). In general, antioxidant activities of functional compounds are highly associated with the analytical methods, and it is difficult to directly compare and interpret patterns of antioxidant activities from various studies. In our study, the polarities of the BFEs differed, which could have influenced their uptake rates and cellular distributions. Further work related to characterizing the complete chemical composition of the samples by liquid chromatography-mass spectrometry needs to be conducted.

Purification, separation, and isolation of bioactive compounds from plants are techniques that have undergone new developments in recent years. The goal when searching for bioactive compounds is to find an appropriate method to screen the source material for its bioactivity, such as antioxidant or cytotoxic properties, combined with simplicity, specificity, and speed. However, little information has been reported on the effects of solvents and the ultrasonic extraction method for Chinese bayberry bioactive compounds. Ultrasound is used to disrupt plant cell walls, which helps improve the solvent's ability to 
640

penetrate cells and obtain higher extraction yields. A smashed sample is mixed with a suitable solvent and placed into an ultrasonic bath, while controlling the temperature and extraction time, and a high extract quality of compounds can be maintained (Garcia-Salas et al., 2010). Corrales et al. (2008) showed that ultrasound can break down grape tissues, and it worked well during the production process and released active compounds in solvents with high efficiency. Mulinacci et al. (2004) confirmed that an ultrasonic method was most effective for extracting phenolic compounds from strawberries compared to other extraction methods. In our study, total phenols from the Dongkui BFE prepared using an ultrasonic method were shown to possess potent in vitro antioxidant activity, which should stimulate research into the contents, capacities, and functions of antioxidant systems in $M$. rubra plants.

$\mathrm{H}_{2} \mathrm{O}_{2}$ can be used as a mediator to induce cytotoxicity, which will create intracellular redox interference, thereby causing perturbations in the antioxidant defense system. The consistent in vitro antioxidant capacity of bayberry cultivars further stimulated us to investigate the ROSscavenging capacity of $\mathrm{H}_{2} \mathrm{O}_{2}$-induced cellular ROS in RAW 264.7 cells. Thus, a concentration of as low as $0.025 \mathrm{mg} / \mathrm{mL}$ can be used in further studies. Furthermore, a higher value for the cell viability indicates the higher $\mathrm{H}_{2} \mathrm{O}_{2}$-scavenging activity of the BFE. The RAW 264.7 murine macrophage cell line was used in this study because it has been widely applied to antioxidant research of traditional herbs (Tuntipopipat et al., 2009). Macrophages are considered to play key roles in local host defense. Inflammatory mediators, such as NO and TNF- $\alpha$, are essential for the host defense system, but excessive production of these mediators at an inflammatory site may cause chronic diseases (Thun et al., 2004). Thus, inhibition of activation of these cells appears to be an important target for treating inflammatory diseases (Lin and Karin, 2007). LPS can stimulate RAW 264.7 macrophages to mimic the condition of excessive ROS production. During LPS stimulation, NO is produced by iNOS (Kubes and McCafferty, 2000), and inhibition of iNOS expression and its activities is well known to be a target for preventing inflammatory diseases and cancer (Surh and $\mathrm{Na}, 2008$ ). Oxidative damage to DNA is one of the most important mechanisms for initiating carcinogenesis, mutagenesis, and cytotoxicity (Prieto et al., 1999). Such damage is usually caused by hydroxyl radicals, the most reactive compound among ROS. The Fenton reaction is complex and capable of generating both hydroxyl radicals and higher oxidation states of ferric iron (Winterbourn, 1995). Yen et al. (2006) revealed the free radical-scavenging and protective effects of lotus seed extracts against reactive nitrogen, sodium nitroprusside, peroxynitrite-induced cytotoxicity, and DNA damage in the macrophage RAW 264.7 cell line. Chao et al. (2015) also reported that the ethanolic extract of red bean (RBE) can diminish $\mathrm{H}_{2} \mathrm{O}_{2}$-induced oxidative damage in $\mathrm{RAW}$ 264.7 macrophages. Phenolic compounds and cyanidin-3$O$-glucoside from the RBE may have efficacy as overall in vitro anti-inflammatory and antioxidant agents. Hwang et al. (2016) investigated the antioxidant activities of Cornus officinalis in RAW 264.7 cells, and showed that protein expressions of antioxidant enzymes $(\mathrm{Cu} / \mathrm{Zn}$ superoxide dismutase (SOD), MnSOD, catalase, and glutathione peroxidase) increased upon treatment with $C$. officinalis extracts. They suggested the therapeutic potential of the $C$. officinalis extract as an antioxidant agent. In the present study, the Dongkui BFE prepared by stirring and ultrasonic methods produced the least amount of $\mathrm{NO}$ secretion, and therefore had the best capacity against $\mathrm{H}_{2} \mathrm{O}_{2}$. The Dongkui BFE offered protection against $\mathrm{H}_{2} \mathrm{O}_{2}$-induced damage in RAW 264.7 cells without affecting the cell viability, and this protective effect is considered, in large part, to be related to the various antioxidants it contains. Total phenolic compounds in the Dongkui BFE may be a major contributor to inhibition of the formation of ROS, and showed anticancer potential in RAW 264.7 cells. Total phenolic compounds are widely recognized as natural molecules with anti-inflammatory effects. Positive correlations were found between the TPC and some antiinflammatory effects of different mushroom extracts (Kim et al., 2008). Therefore, the Dongkui BFE can be used to prevent and treat oxidative stress-related disorders. Further studies should focus on the valuable outcomes of its effects in animal models.

The total flavonoid intake of an average American is approximately $20 \mathrm{mg} /$ day, and for Japanese it is around 63 $\mathrm{mg}$ /day from plant-based foods (Beecher, 2003). Therefore, the antioxidant effect of the BFE by various extraction methods can be valuable, particularly for finding an inexpensive source of natural antioxidants and functional foods. The Dongkui BFE prepared using ultrasonics revealed the potential to be developed as an active ingredient or food additive, thereby increasing the economic value of Taiwanese bayberries for the food industry. Myrica rubra plants are abundant on the island, and the fruit that is marketed in Taiwan varies widely in antioxidant potentials and thus may impart different health benefits to consumers. Bayberry fruits with high antioxidant values prepared by ultrasonic extraction can be used to develop products with high nutraceutical value, which can play significant roles in providing good nutrition and improving human health. People can consume the BFE as a low-cost, nutritious food and use it as a low-cost medicine to treat various diseases. The obvious antioxidant activity of the Dongkui BFE prepared using ultrasonics confirms its important role in the bioactivity of $M$. rubra plants. Determination of the TPC of the BFE is valuable in increasing the bioavailability of bayberry products, and the effective dose in in vivo studies is worthy of further investigation.

\section{Conclusions}

We identified for the first time that Taiwanese bayberry fruit contains potent polar antioxidants that are responsible for protecting against oxidative damage. Myrica rubra variety Dongkui showed higher TPCs and antioxidant activities compared to Nakai. Different extraction methods of the BFEs displayed variable levels of antioxidant substances, and the Dongkui BFE prepared using ultrasonics possessed higher amounts of total phenols and exhibited high free radical-scavenging activities as evaluated using DPPH, ABTS, $\mathrm{H}_{2} \mathrm{O}_{2}$, and the reducing power. In 
addition, the $85 \%$ ethanolic BFE was proven to be noncytotoxic and to have significant anti-inflammatory effects in a mouse RAW 264.7 cell model. These strong oxidationpreventive and radical-scavenging activities of the BFE may be associated with its rich content of total phenols. BFEs exhibited higher in vitro and ex vivo antioxidant activities and possessed protective capabilities for the biological membrane system. Therefore, the BFE can be used to prevent and treat oxidative stress-related disorders. Further studies are warranted to isolate and identify individual phenolic compounds from the alcoholic extract of $M$. rubra fruits to better understand the biological mechanisms. Overall, we believe that the hydroalcoholic extract of $M$. rubra fruit can be a multifunctional food additive and can be widely applied in the field of medicine in the near future.

\section{References}

Azmir J,Zaidul ISM, Rahman MM, SharifKM, Mohamed A, Sahena F, .. Omar AKM (2013). Techniques for extraction of bioactive compounds from plant materials: a review. Journal of Food Engineering $117(4): 426-436$.

Beecher GR (2003). Overview of dietary flavonoids: Nomenclature, occurrence and intake. Journal of Nutrients 133(10):3248-3254.

Chao WW, Chung YC, Shih IP, Wang HY, Chou ST, Hsu CK (2015). Red bean extract inhibits lipopolysaccharide-induced inflammation and $\mathrm{H}_{2} \mathrm{O}_{2}$-induced oxidative stress in Raw 264.7 macrophages. Journal of Medicine Food 18(7):724730.

Chen W, Zhao J, Bao T, Xie J, Liang W, Gowd V (2016). Comparative study on phenolics and antioxidant property of some new and common bayberry cultivars in China. Journal of Functional Foods 27:472-482.

Corrales M, Toepfl S, Butz P, Knorr D, Tauscher B (2008). Extraction of anthocyanins from grape by-products assisted by ultrasonics, high hydrostatic pressure or pulsed electric fields: A comparison. Innovative Food Science \& Emerging Technoogies 9(1):85-91.

Farrell NJ, Norris GH, Ryan J, Porter CM, Jiang C, Blesso CN (2015). Black elderberry extract attenuates inflammation and metabolic dysfunction in diet-induced obese mice. British Journal of Nutrition 114(8):1123-1131.

Farombi EO, Hansen M, Ravn-Haren G, Moller P, Dragsted LO (2004). Commonly consumed and naturally occurring dietary substances affect biomarkers of oxidative stress and DNA damage in healthy rats. Food and Chemical Toxicology 42(8):1315-1322.

Garcia-Salas P, Morales-Soto A, Segura-Carretero A, Fernandez-Gutierrez A (2010). Phenolic-compound-extraction systems for fruit and vegetable samples. Molecules 15(12):8813-8826.

Ghafoor K, Hui T, Choi YH (2011). Optimization of ultrasound-assisted extraction of total anthocyanins from grape peel. Journal of Food Biochemistry35(3):735-746.

Green L C, Wagner DA, Glogowski J, Skipper P L, Wishnok JS, Tannenbaum SR (1982). Analysis of nitrate, nitrite, and nitrate in biological fluids. Analytical Biochemistry 126(1):131-138.

Hong Y, Lin S, Jiang Y, Ashraf M (2008). Variation in contents of total phenolics and flavonoids and antioxidant activities in the leaves of 11 Eriobotrya species. Plant Foods for Human Nutrition 63(4):200-204.
Huang H, Sun Y, Lou S, Li H, Ye X (2014). In vitro digestion combined with cellular assay to determine the antioxidant activity in Chinese bayberry (Myrica rubra Sieb. et Zucc.) fruits: A comparison with traditional methods. Food Chemistry 146:363-370.

HwangKA, Hwang YJ, SongJ (2016). Antioxidant activities and oxidative stress inhibitory effects of ethanol extracts from Cormus officinalis on raw 264.7 cells. BMC Complementary and Alternative Medicine 16(1):196.

JuJ, Yaoa W, Sun S, Guo Y, Cheng Y, Qian H, Xie Y (2018). Assessment of the antibacterial activity and the main bacteriostatic components from bayberry fruit extract. International Journal of Food Properties 21(1):1043-1051.

Juang L, Gao X Y, Mai ST, Lee CH, Lee MC, Yao CL (2018). Safety assessment, biological effects, and mechanisms of Myrica rubra fruit extract for anti-melanogenesis, antioxidation, and free radical scavenging abilities on melanoma cells. Journal of Cosmetic Dermatology 18:1-11.

Jurgonski A, Juskiewicz J, Zdunczyk Z (2008). Ingestion of black chokeberry fruit extract leads to intestinal and systemic changes in a rat model of prediabetes and hyperlipidemia. Plant Foods for Human Nutrition 63(4):176-182.

Kashiwada Y, Aoshima A, Ikeshiro Y, Chen YP, Furukawa H, ... Lee KH (2005). Anti-HIV benzylisoquinoline alkaloids and flavonoids from leaves of Nelumbo nucifera, and structure-activity correlations with related alkaloids. Bioorganic \& Medicinal Chemistry 13(2):443-448.

Kim MY, Seguin P, Ahn JK, Kim J, Chun SC, Kim H (2008). Phenolic compound concentration and antioxidant activities of edible and medicinal mushrooms from Korea. Journal of Agricultural and Food Chemistry 56(16):7265-7270.

Kubes P, McCafferty DM (2000). Nitric oxide and intestinal inflammation. The American Journal of Medicine 109(2):150-158.

Kumoro C, Hartati I (2015). Microwave assisted Extraction of Dioscorin from Gadung (Dioscorea Hispida Dennst) tuber flour. Procedia Chemistry 14:47-55.

Lee AL, Yu YP, Hsieh JF, Kuo MI, Ma YS, Lu CP (2018). Effect of germination on composition profiling and antioxidant activity of the polysaccharide-protein conjugate in black soybean [Glycine max (L.) Merr.]. International Journal of Biological Macromolecules 113:601606.

Li Y, Fabiano-Tixier AS, Tomao V, Cravotto G, Chemat F (2013). Green ultrasound-assisted extraction of carotenoids based on the bio-refinery concept using sunflower oil as an alternative solvent. Ultrasonics Sonochemistry 20(1):12-18.

Lin WW, Karin MA (2007). A cytokine-mediated link between innate immunity, inflammation, and cancer. Journal of Clinical Investigation 117(5):1175-1183.

Lu CP, Lin CT, Chang CM, Wu SH, Lo LC (2011). Nitrophenylboronic acids as highly chemoselective probes to detect hydrogen peroxide in foods and agricultural products. Journal of Agricultural and Food Chemistry 59(21):11403-11406.

Medina-Torres N, Ayora-Talavera T, Espinosa-Andrews H, SánchezContreras A, Pacheco N (2017). Ultrasound assisted extraction for the recovery of phenolic compounds from vegetable sources. Agronomy $7(3): 47$. 
642

Meireles M, Rodriguez-Alcala LM, Marques C, Norberto S, Freitas J, Fernandes I, Calhau C (2016). Effect of chronic consumption of blackberry extract on high-fat induced obesity in rats and its correlation with metabolic and brain outcomes. Food \& Functional 7(1):127-139.

Mulinacci N, Prucher D, Peruzzi M, Romani A, Pinelli P, Giaccherini C, Vincieri FF (2004). Commercial and laboratory extracts from artichoke leaves: Estimation of caffeoyl esters and flavonoidic compounds content. Journal of Pharmaceutical and Biomedical Analysis 34(2):349-357.

Padmavati MN, Sakthivel K, Tahara V, Reddy AR (1997). Differential sensitivity of rice pathogens to growth inhibition by flavonoids. Phytochemistry 46(3):499-502.

Pinelo M, Manzocco L, Nunez MJ, Nicoli MC (2004). Interaction among phenols in food fortification: Negative synergism on antioxidant capacity.Journal of Agricultural and Food Chemistry 52(5):1177-1180.

Prieto P, Pineda M, Aguilar M (1999). Spectrophotometric quantitation of antioxidant capacity through the formation of phosphomolybdenum complex: specific application to determination of vitamin E. Analytical Biochemistry 269(2):337-341.

Radojković M, Zeković Z, Jokić S, Vidović S, Lepojević Ž, Milošević S (2012). Optimization of solid-liquid extraction of antioxidants from black mulberry leaves by response surface methodology. Food Technology and Biotechnology 50(2):167-176.

Re R, Pellegrini N, Proteggente A, Pannala A, Yang M, Rice-Evans C (1999). Antioxidant activity applying an improved ABTS radical cation decolorication assay. Free Radical Biology \& Medicine 26(9-10):12311237.

Silva BJC, Seca AML, Barreto MC, Pinto DCGA (2015). Recent breakthroughs in the antioxidant and anti-inflammatory effects of Morella and Myrica species. International Journal of Molecular Science 16(8):17160-17180.

Sun C, Zheng Y, Chen Q (2012). Purification and anti-tumour activity of cyanidin-3-O-glucoside from Chinese bayberry fruit. Food Chemistry 131(4):1287-1294.

Surh YJ, Na HK (2008). NF-kB and Nrf2 as prime molecular targets for chemoprevention and cytoprotection with anti-inflammatory and antioxidant phytochemicals. Genes and Nutrition 2(4):313-317.

Thun MJ, Henley SJ, Gansler T (2004). Inflammation and cancer: an epidemiological perspective. Novartis Foundation Symposia 256:6-21.
Tuntipopipat S, Muangnoi C, Failla ML (2009). Anti-inflammatory activities of extracts of Thai spices and herbs with lipopolysaccharideactivated RAW 264.7 murine macrophages. Journal of Medicinal Food 12(6):1213-1220.

Vega Arroy JD, Ruiz-Espinosa H, Luna-Guevara JJ, Luna-Guevara ML, Hernandez-Carranza P, ... Ochoa-Velasco CE (2017).Effect of solvents and extraction methods on total anthocyanins, phenolic compounds and antioxidant capacity of Renealmia alpinia (Rottb.) mass peel. Czech Journal of Food Sciences 35(5):456-465.

WangK, Cao S, Jin P, Rui H,ZhengY (2010). Effect of hot air treatment on postharvest mould decay in Chinese bayberry fruit and the possible mechanisms. International Journal of Food Microbiology 141(1-2):1116.

WangL, Weller CL (2006). Recent advances in extraction of nutraceuticals from plants. Trends in Food Science and Technology 17(6):300-312.

Winterbourn CC (1995). Toxicity of iron and hydrogen peroxide: the Fenton reaction. Toxicology Letters 82:969-974.

Yang YP, Lu, SY (1996). Flora of Taiwan (vol. 2) second edition. The Committee 2:19.

Yang Z, Cao S, Zheng Y (2011). Chinese bayberry fruit extract alleviates oxidative stress and prevents 1, 2-dimethylhydrazine-induced aberrant crypt foci development in rat colon carcinogenesis. Food Chemistry 125(2):701-705.

Yao WR, Wang HY, Wang ST, Sun SL, Zhou J, Luan YY (2011). Assessment of the antibacterial activity and the antidiarrheal function of flavonoids from bayberry fruit. Journal of Agricultural and Food Chemistry 59(10):5312-5317.

Yen GC, Duh PD, Su J, Yeha CT, Wu CH (2006). Scavenging effects of lotus seed extracts on reactive nitrogen species. Food Chemistry 94(4):596-602

Zhang X, Lv Q, Jia S, Chen Y, Sun C, Li X, Chen K (2016). Effects of favonoid-rich Chinese bayberry (Morella rubra Sieb.Et Zucc.) fruit extract on regulating glucose and lipid metabolism in diabetic kk-Ay mice. Food and Functional 7(7):3130-3140.

Zhou SH, Fang ZX, Lu Y, Chen JC, Liu DH, Ye XQ (2009). Phenolics and antioxidant properties of bayberry (Myrica rubra Sieb. et Zucc.) pomace. Food Chemistry 112(2):394399. 